\title{
MicroRNA-217, down-regulated in clear cell renal cell carcinoma and associated with lower survival, suppresses cell proliferation and migration
}

\author{
H. LI ${ }^{\ddagger}$ J. ZHAO ${ }^{\ddagger}$ J. W. ZHANG, Q. Y. HUANG, J. Z. HUANG, L. S. CHI, H. J. TANG, G. Q. LIU, D. J. ZHU, W. M. MA* \\ Foshan Maternal and Child Health Care Hospital, Foshan, China \\ *Correspondence: betterzhao@163.com \\ ${ }^{*}$ Contributed equally to this work.
}

Received February 4, 2013/ Accepted March 13, 2013

\begin{abstract}
Aberrantly expressed microRNAs (miRNAs) are frequently correlated with a variety of human cancers, including clear cell renal cell carcinoma (ccRCC). In this study, we determined the expression patterns of miR-217 in ccRCC, and tested its effect on cancer cell proliferation and migration. The expression levels of miR-217 were determined in 54 ccRCC samples using Real-Time qPCR. 786-O and ACHN cells were transfected with miR-217 mimics or miRNA mimics control. Cell proliferation and migration were evaluated by MTT assay and scratch-wound assay, respectively. We found that miR-217 was down-regulated in ccRCC compared to paired normal tissue. Lower miR-217 expression levels were associated with higher tumor grade and stage. All patients with high miR-217 expression survived 5 years, while with low miR-217 expression, only $40 \%$ survived. Cell proliferation inhibition and decreased motility were observed in cells transfected with the miR-217 mimics. In conclusion, miR-217 plays a tumor suppressor role in ccRCC.
\end{abstract}

Key words: miR-217, clear cell renal cell carcinoma, survival, proliferation, migration

Renal cell carcinoma (RCC) is one of the most lethal genitourinary neoplasms with an incidence of approximately 5-10 per 100,000 and accounts for $2-3 \%$ of all cancers [1].Clear cell renal carcinoma (ccRCC) is the most common subtype $(\sim 70 \%)$ of renal cell carcinoma [2]. Although many genetic and epigenetic changes are found to be associated with ccRCC, the carcinogenesis is still far from clearly understood.

microRNAs (miRNAs) are a class of non-coding RNAs that play critical roles in carcinogenesis [3]. Many miRNAs are abnormally expressed in different types of clinical cancer samples [4]. Deregulated miRNAs have generated great interest in cancer diagnosis and therapy. Numerous studies are focused on the potential applications of miRNAs in human cancers [56]. miRNAs as predictive biomarkers or therapeutic targets in ccRCC remain to be discovered .

Based on the deep sequencing results [7], we selected miR-217 as the possible tumor marker for ccRCC. We hypothesized that miR-217 may have roles in tumor cell growth and migration.

As a potential tumor suppressor, miR-217 has been shown to be aberrantly expressed in several types of tumors, such as pancreatic ductal adenocarcinoma [8] and uterine leiomyoma [9]. Previous work has also demonstrated that miR-217 can down-regulate the tumor suppressor gene PTEN in kidney disorders [10]. However, no researches apparently have been conducted to investigate the role of miR-217 in ccRCC.

In the present study, the expression patterns of miR-217 in ccRCC and paired histologically normal tissue were investigated by using Real-Time qPCR. Correlation between the expression of miR-217 and survival in patients with ccRCC was also determined by Kaplan-Meier method. Cell proliferation and migration were measured after overexpression of miR-217 in 786-O and ACHN cells. To the best of our knowledge, this is the first report showing the correlation of miR-217 expression with poor prognosis and the background of its functional role in ccRCC.

\section{Materials and methods}

Clinical sample collection. Fifty-four patients with ccRCC participated in the study. These patients received radical nephrectomy. Clear cell renal carcinoma was diagnosed 
histopathologically. Paired samples of ccRCCs and adjacent normal tissues were snap-frozen in liquid nitrogen immediately after resection. Written informed consents from all patients were obtained and this study was approved by Institutional Review Board of Foshan Maternal and Child Health Care Hospital (Foshan, China). The clinical data of the patients with ccRCC were shown in Table 1.

Cell lines and cell culture. The human renal clear-cell carcinoma lines 786-O and ACHN were obtained from the Institute of Cell Research, Chinese Academy of Sciences, Shanghai, China. Cells were cultured in RPMI 1640 medium supplemented with $10 \%$ fetal bovine serum (Invitrogen) at $37^{\circ} \mathrm{C}$ in a $5 \% \mathrm{CO}_{2}$ atmosphere.

Cell transfection.miR-217 mimics and the miRNA mimics control (Dharmacon) were transfected into cells using Hiperfect Transfection Reagent (Invitrogen) according to the manufacturer's protocols.

RNA extraction and real-time quantitative PCR. Total RNA was extracted from ccRCC samples and matched histologically normal tissues or cell lines using TRIzol (Invitrogen) according to the manufacture's protocol. The cDNA strand was synthesized from total RNA with the RevertAidTM First Strand cDNA Synthesis Kit (Fermentas, Hanover, MD). The primer sequences were as follows: miR-217 forward primer: 5'CGCTCTACTGCATCAGGAACTGA-3', reverse primer: 5'-GTGCAGGGTCCGAGGT-3'; U6 forward primer: 5'GCTTCGGCAGCACATATACTAAAAT-3', reverse primer: 5'-CGCTTCACGAATTTGCGTGTCAT-3'. PCRs were set up in a total volume of $20 \mu$, including $10 \mu \mathrm{l}$ of All-inOneTMqPCR Mix (GeneCopoiea Inc., Rockville, MD), $0.4 \mu \mathrm{l}$ of forward primer, $0.4 \mu \mathrm{l}$ of reverse primer, $1 \mu \mathrm{l}$ of FirstStrand cDNA, $0.4 \mu \mathrm{l}$ of $50 \times$ ROX Reference Dye and $7.8 \mu \mathrm{l}$

Table 1. Clinical and pathology characteristics of 54 patients.

\begin{tabular}{lc}
\hline Clinical-pathologic variables & $\mathrm{N}(\%)$ \\
\hline All cases & 54 \\
$\quad$ Male & $40(74 \%)$ \\
$\quad$ Female & $14(26 \%)$ \\
Age & \\
$\quad>50$ & $50(93 \%)$ \\
$\quad \leq 50$ & $4(7 \%)$ \\
Histological type & \\
Clear cell renal carcinoma & $54(100 \%)$ \\
Others & 0 \\
Pathological grade (WHO) & \\
G1 & $25(46 \%)$ \\
G2 & $21(39 \%)$ \\
G3 & $8(15 \%)$ \\
AJCC clinical stage & \\
$\mathrm{T}_{1}$ & $26(48 \%)$ \\
$\mathrm{T}_{2}$ & $21(39 \%)$ \\
$\mathrm{T}_{3} \mathrm{~T}_{4}$ & $7(13 \%)$ \\
\hline
\end{tabular}

of double-distilled water. The reactions were performed in the ABI PRISM 7000 Fluorescent Quantitative PCR System (Applied Biosystems, Foster City, CA). The PCR cycling parameters were: $95^{\circ} \mathrm{C}$ for $15 \mathrm{~min}$, followed by 40 cycles of $94{ }^{\circ} \mathrm{C}$ for $15 \mathrm{~s}, 55^{\circ} \mathrm{C}$ for $30 \mathrm{~s}$ and $72^{\circ} \mathrm{C}$ for $30 \mathrm{~s}$. Expression fold changes were calculated using $2^{-\Delta \Delta \mathrm{Ct}}$ methods.

Cell proliferation assay. Cell proliferation was measured by 3-[4,5-dimethylthiazol-2-yl]-2,5-diphenyl-tetrazolium bromide (MTT) assay. Cells were grown in a 96-well plate for $24 \mathrm{~h}$, transfected with miR-217 mimics or miRNA mimics control and cultured in normal medium. Cells were then incubated in $0.1 \mathrm{mg} / \mathrm{ml} \mathrm{MTT}$ at $37^{\circ} \mathrm{C}$ for $4-6 \mathrm{~h}$ and lysed in dimethyl sulfoxide (DMSO) at room temperature for $10 \mathrm{~min}$ at $0,24,48$, and $72 \mathrm{~h}$ after transfection. The absorbance in each well was measured at $490 \mathrm{~nm}$ by a microplate reader (Bio-Rad, Hercules, CA). Each experiment was done at least three times.

Cell migration assay .Cells were cultured and transfected with either miR-217 mimics or miRNA mimics control. Cells were scratched in the monolayer and cultured in normal medium. Photographic images were taken from each well immediately and again after $24 \mathrm{~h}$ using a digital camera system. Cell migration distance $(\mu \mathrm{m})$ was calculated using the software program HMIAS-2000. Each experiment was repeated for at least three times.

Statistical analyses. Data analyses were performed by ANOVA test or Student's t-test, respectively, using the SPSS (Version 17.0 SPSS Inc.). Survival curves were plotted by the Kaplan-Meier method and compared by the log-rank test. $\mathrm{P}<0.05$ was considered to be statistically significant.

\section{Results}

miR-217 was down-regulated in ccRCC. The relative expression levels of miR-217 were determined using Real-Time qPCR in a total of 54 patients with ccRCC. The miR-217 expression fold change (ccRCC /matched histologically normal tissue) in each patient (from No. 1 to No. 54) is shown in Figure $1 \mathrm{~A}$. miR-217 was down-regulated in ccRCC compared to matched histologically normal tissue. The miR-217 expression fold change (ccRCC / matched histologically normal tissue) was 0.47 (Fig. 1B). We analyzed expression differences according to grading and staging. We found significant stepwise decreases in miR-217 expression with advancing tumor grade (Fig. 1C) and stage (Fig. 1D).

Correlation of miR-217 expression with survival in ccRCC. Low expression level of miR-217 appears to be associated with low survival in patients with ccRCC. For patients with high miR-217 expression (T/N $>0.94$ ), all survived 5 years after surgery, while for those with low miR-217 expression ( $\mathrm{T} / \mathrm{N}<0.49$ ), only $40 \%$ survived (Figure 2 ). The survival curve was based on the number of patients (43) for whom we had the survival information.

Overexpression of miR-217 by miR-217 mimics in 786-O and ACHN Cells. 786-O and ACHN cells were transfected 

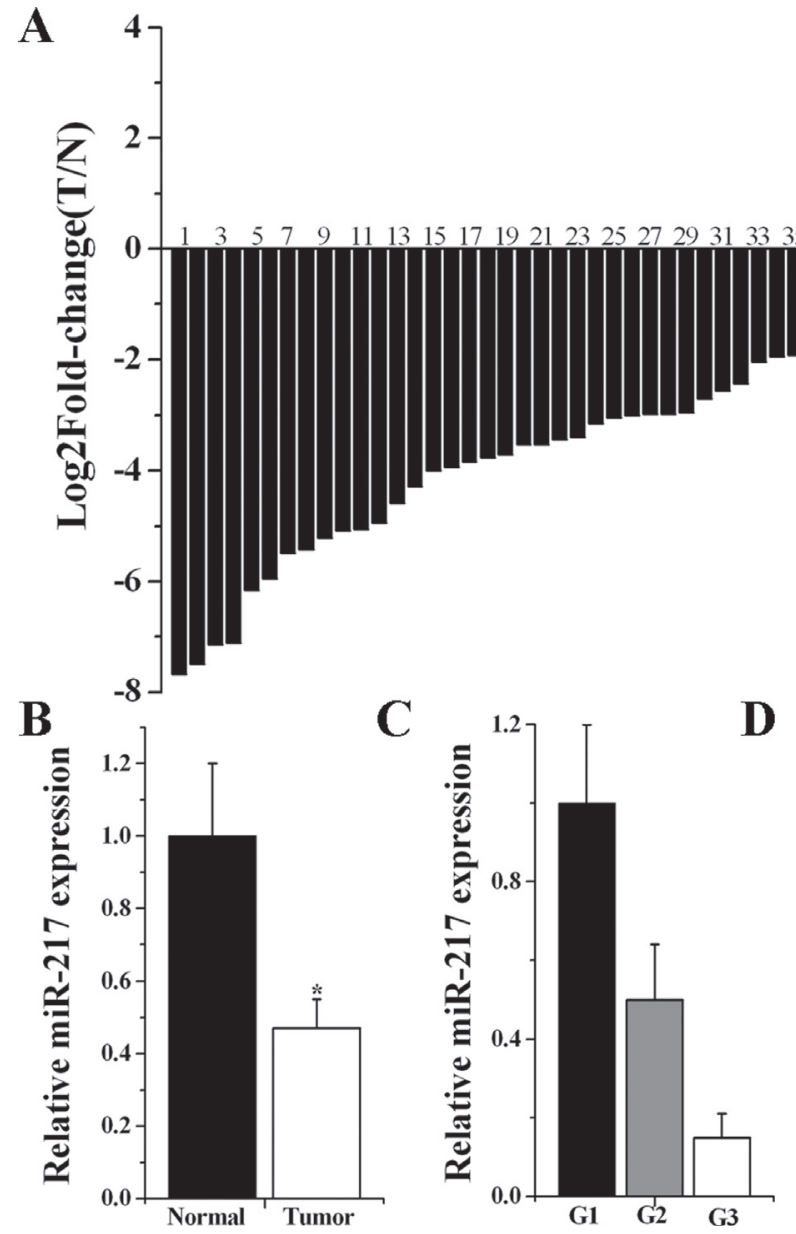

with either miR-217 mimics or miRNA mimics control and cultured in normal medium. Forty-eight hours after transfection, the cells were collected. Then the miR-217 expression levels in miR-217 mimics or miRNA mimics control transfected cells were analyzed. The relative expression levels of miR-217 in 786-O and ACHN cells treated with miR-217 mimics were significantly up-regulated by $18.05 \pm 2.82$ fold $(\mathrm{p}<0.01)$ and $20.43 \pm 3.42$ fold $(\mathrm{p}<0.01)$, respectively. Data are shown as mean $\pm \mathrm{SD}$. Each experiment was performed in triplicate for three independent times.

Overexpression of miR-217 inhibited cell proliferation. To investigate the possible impact of miR-217 on the proliferation of ccRCC cells, the cell proliferation changes of 786-O and ACHN cells were determined by MTT assay. Cell growth inhibitions were obtained in both cell lines. Significant differences were demonstrated between the miRNA mimics control and miR-217 mimics-transfected cells (Fig. 3A).

Overexpression of miR-217 inhibited cell migration. To investigate the possible impact of miR-217 on the migration of ccRCC cells, the cell motility changes of 786-O and $\mathrm{ACHN}$ cells were determined by in vitro scratch assay.

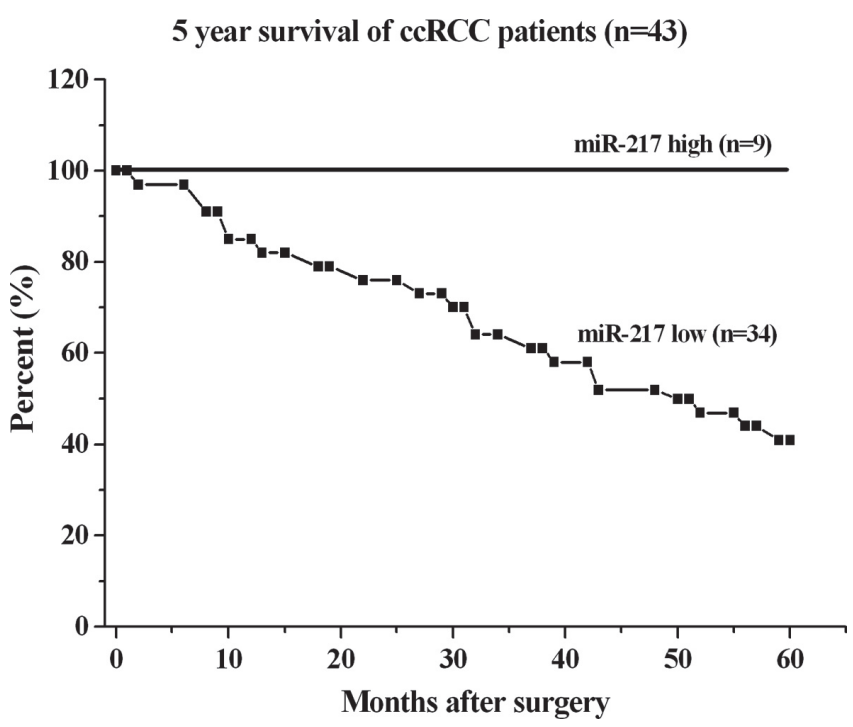

Figure 2. Correlation of miR-217 expression with 5 year survival of ccRCC patients. The survival rate of the group with low expression of miR-217 was lower than that of the group with high expression of miR-217(logrank test, $\mathrm{p}<0.01)$.
Figure 1. The expression of $\mathrm{miR}-217$ in ccRCC. The relative miR-217 expression levels were determined using Real-Time qPCR. (A): $\mathrm{T}$ stands for tumor, $\mathrm{N}$ stands for normal tissue. The heights of the columns in the chart represent the $\log 2$-transformed fold changes (tumor/normal) in miR-217 expression in 54 patients (from No. 1 to No. 54). (B): miR-217 was down-regulated in ccRCC compared to paired histologically normal tissue in 54 patients $(p<0.01)$. (C): Lower miR-217 expression level was associated with higher tumor grade $(\mathrm{p}<0.01)$. (D): Lower miR-217 expression level was associated with higher tumor stage $(p<0.01)$. Data are shown as mean $\pm S E M$ in $B, C$, and $D$. 
A

786-O

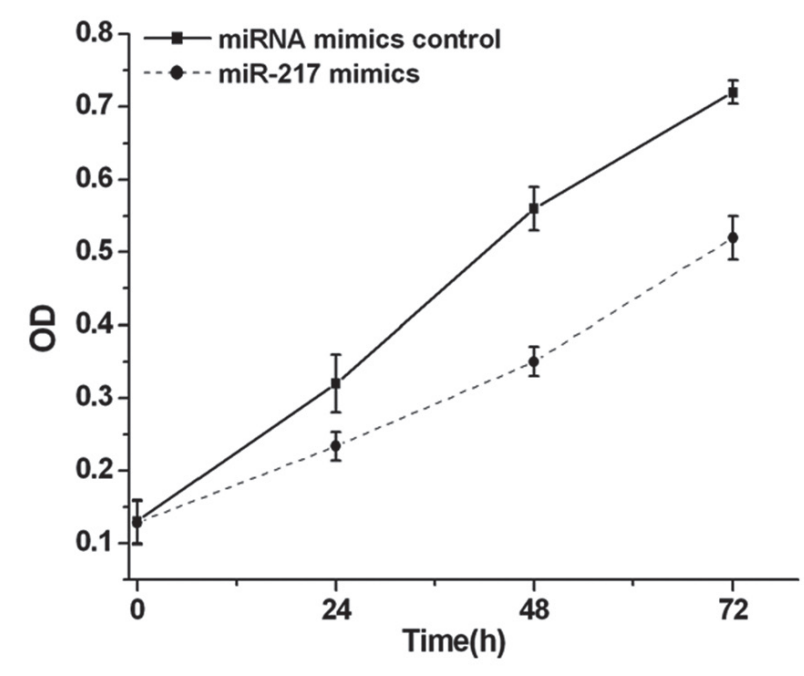

786-O

B

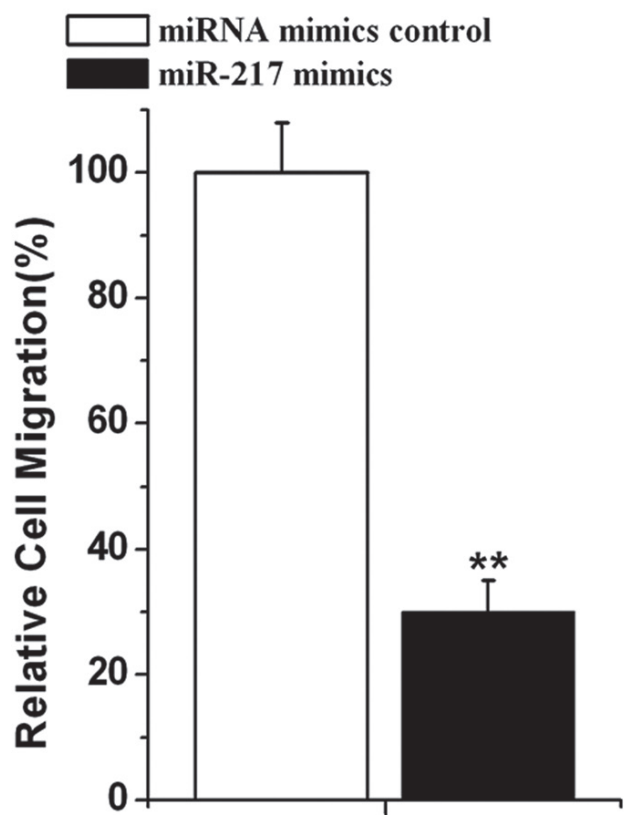

ACHN

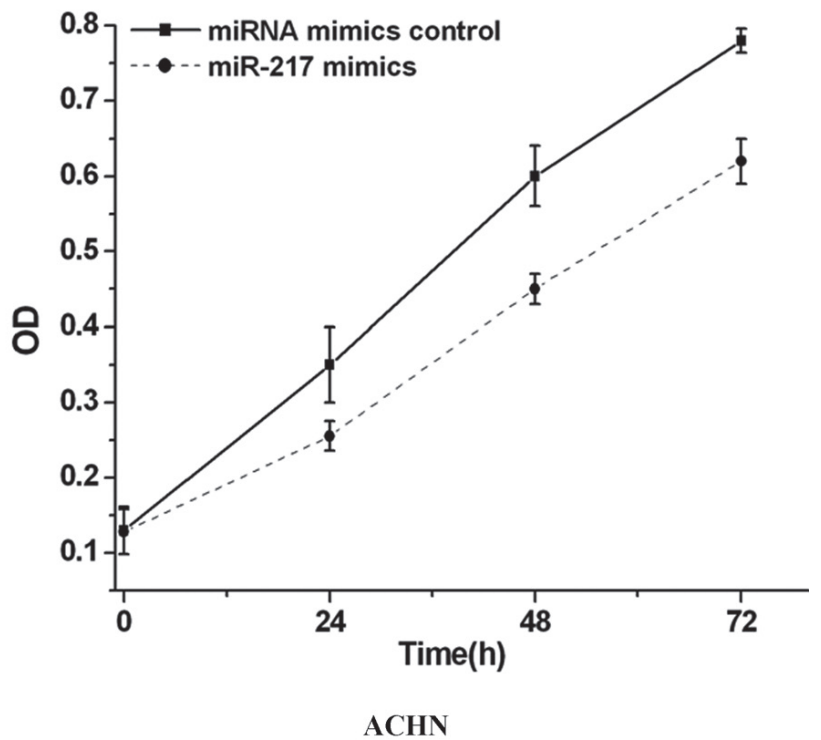

miRNA mimics control miR-217 mimics

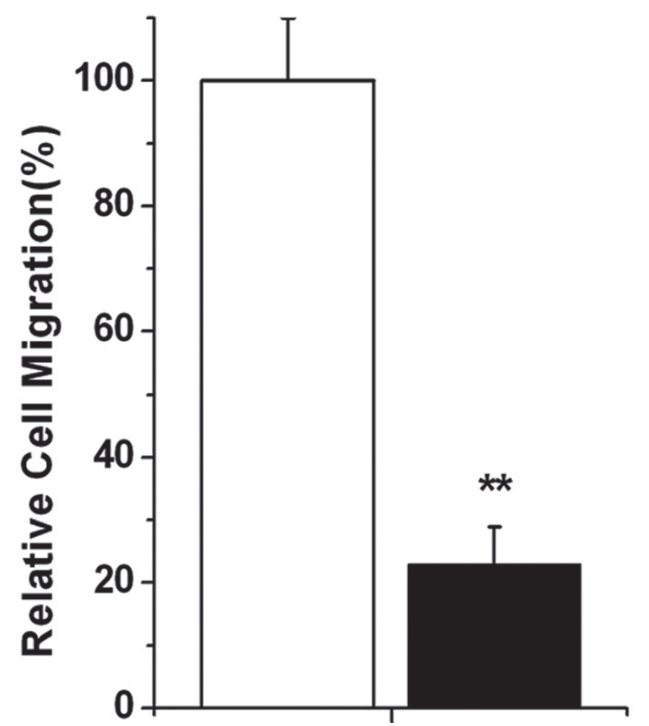

Figure 3. Involvement of miR-217 in cell proliferation and migration. (A): Overexpression of miR-217 inhibited cell proliferation ( $p<0.01$ and $p<0.01$, respectively); (B): Overexpression of miR-217 inhibited cell migration ( $<<0.01$ and $p<0.01$, respectively).

Decreased cell motility was observed in 786-O and ACHN cells (Fig. 3B).

\section{Discussion}

miRNAs are emerging as endogenous triggers of the RNA interference pathway and play a key role in carcinogenesis. Recent studies have identified a number of miRNAs as potential tumor markers for cancers [11]. Some of them function either as tumor suppressors or as oncogenes. Several miRNAs have been shown to be up-regulated in human ccRCC tissue samples, such as miR-21-3p, miR-200c, miR-210-3p and miR451-3p. In contrast, miR-214, miR-215 and miR-429 have been shown to be down-regulated in human ccRCC specimens [12-13]. Although a considerable number of miRNAs have already been reported to be associated with the progression of ccRCC, the results of the genome-wide miRNA profiling studies are not consistent. So there is still a growing need for novel predictive and prognostic markers to improve the treatment outcomes of patients with ccRCC [14]. 
miR-217 is progressively expressed in endothelial cells during aging and is negatively correlated with SirT1 expression [15]. In cultured mouse AML-12 hepatocytes and in mouse livers, miR-217 promotes ethanol-induced fat accumulation by down-regulating SirT1 [16]. miR-217 also influences Tatinduced HIV-1 long terminal repeat (LTR) transactivation by down-regulation of SirT1 expression [17].It has been reported that miR-217 acts as a potential tumor suppressor in pancreatic ductal adenocarcinoma by targeting KRAS [8]. Overexpression of miR-217 can reverse the malignant behavior of pancreatic ductal adenocarcinoma cells. miR-217 is also found to be one of the top five significantly de-regulated miRNAs in human uterine leiomyoma (ULM) [9].These studies provide evidences for the important function of miR-217 in the pathogenesis of human diseases. However, its role in ccRCC remains largely unknown.

In the present study, we found that miR-217 was downregulated in ccRCC compared to paired histologically normal tissue. Lower level expression levels of miR-217 were associated with higher tumor grade and stage. Down-regulation of miR-217 in ccRCC was related to lower survival of kidney cancer patients. Thus we believe that miR-217 can be used as a tumor marker for ccRCC.

The differential miR-217 expression pattern may be helpful in developing gene therapy for ccRCC. To prove this possibility, we determine the possible impact of miR-217 on ccRCC cells. Cell proliferation inhibition and decreased motility were observed in miR217-transfected 786-O and ACHN cells. These observations suggest that down-regulated miR-217 may play roles in carcinogenesis via deregulating proliferation and migration related genes in ccRCC. In vivo studies are still needed to further elucidate the effects of miR-217 on tumor growth and metastasis of ccRCC cells.

In summary, miR-217 may play a tumor suppressor role in ccRCC. The differential expression patterns of miR-217 may have implications in guiding diagnosis and treatment of ccRCC.

Acknowledgements: We are indebted to the coworkers, whose names were not included in the author list, but who contributed to this work.

\section{References}

[1] JEMAL A, SIEGEL R, WARD E, HAO Y, XU J et al: Cancer statistics. CA Cancer J Clin 2008; 58: 71-96, http://dx.doi. org/10.3322/CA.2007.0010

[2] RINI BI, CAMPBELL SC, ESCUDIER B: Renal cell carcinoma. Lancet 2009; 373: 1119-1132, http://dx.doi.org/10.1016/ S0140-6736(09)60229-4

[3] IORIO MV, CROCE CM: microRNA involvement in human cancer. Carcinogenesis 2012; 33: 1126-1133, http://dx.doi. org/10.1093/carcin/bgs140

[4] MELO SA, ESTELLER M: Dysregulation of microRNAs in cancer: playing with fire. FEBS Lett 2011; 585: 2087-2099, http://dx.doi.org/10.1016/j.febslet.2010.08.009
[5] SCHOOF CR, BOTELHO EL, IZZOTTI A, VASQUES L R: MicroRNAs in cancer treatment and prognosis. Am J Cancer Res 2012; 2: 414-433,

[6] LIU Y, HAN Y, ZHANG H, NIE L, JIANG Z et al: Synthetic miRNA-Mowers Targeting miR-183-96-182 Cluster or miR210 Inhibit Growth and Migration and Induce Apoptosis in Bladder Cancer Cells. 2012; PLoS One 7: e52280, http://dx.doi. org/10.1371/journal.pone.0052280

[7] ZHOU L, CHEN J, LI Z, LI X, HU X et al: Integrated profiling of microRNAs and mRNAs: microRNAs located on Xq27. 3 associate with clear cell renal cell carcinoma. PLoS One 5: e15224,2010. http://dx.doi.org/10.1371/journal. pone. 0015224

[8] ZHAO WG, YU SN, LU ZH, MA YH, GU YM et al: The miR-217 microRNA functions as a potential tumor suppressor in pancreatic ductaladenocarcinoma by targeting KRAS. Carcinogenesis2010, 31: 1726-1733. http://dx.doi. org/10.1093/carcin/bgq160

[9] GEORGIEVA B, MILEV I, MINKOV I, DIMITROVA I, BRADFORD AP et al: Characterization of the uterine leiomyoma microRNAome by deep sequencing. Genomics 2012; 99: 275-281. http://dx.doi.org/10.1016/j.ygeno.2012.03.003

[10] KATO M, PUTTA S, WANG M, YUAN H, LANTING L et al: TGF-beta activates Akt kinase through a microRNA-dependent amplifying circuit targeting PTEN. Nat Cell Biol 2009; 11: 881-889. http://dx.doi.org/10.1038/ncb1897

[11] ANINDO MI, YAQINUDDIN A: Insights into the potential use of microRNAs as biomarker in cancer. Int J Surg 2012; 10: 443-449. http://dx.doi.org/10.1016/j.ijsu.2012.08.006

[12] OSANTO S, QIN Y, BUERMANS HP, BERKERS J, LERUT E et al: Genome-wide microRNA expression analysis of clear cell renal cell carcinoma by next generation deep sequencing. PLoS One 2012; 7: e38298. http://dx.doi.org/10.1371/journal. pone. 0038298

[13] WHITE NM, KHELLA HW, GRIGULL J: miRNA profiling in metastatic renal cell carcinoma reveals a tumour-suppressor effect for miR-215. Br J Cancer 2011; 105: 1741-1749. http://dx.doi.org/10.1038/bjc.2011.401

[14] AL-ALI BM, RESS AL, GERGER A, PICHLER M: MicroRNAs in renal cell carcinoma: implications for pathogenesis, diagnosis, prognosis and therapy. Anticancer Res 2012, 32: 3727-3732.

[15] MENGHINI R, CASAGRANDE V, CARDELLINI M, MARTELLI E, TERRINONI A et al: MicroRNA 217 modulates endothelial cell senescence via silent information regulator 1. Circulation 2009,120: 1524-1532. http://dx.doi.org/10.1161/ CIRCULATIONAHA.109.864629

[16] YIN H, HU M, ZHANG R, SHEN Z, FLATOW L et al: MicroRNA-217 promotes ethanol-induced fat accumulation in hepatocytes by down-regulating SIRT1. J Biol Chem 2012; 287: 9817-9826. http://dx.doi.org/10.1074/jbc. M111.333534

[17] ZHANG HS, WU TC, SANG WW, RUAN Z: MiR-217 is involved in Tat-induced HIV-1 long terminal repeat (LTR) transactivation by down-regulation of SIRT1. Biochim Biophys Acta 2012; 1823: 1017-1023. 